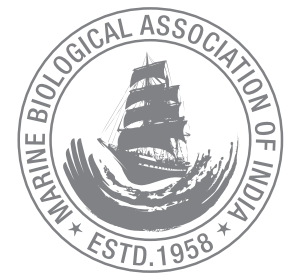

\title{
Zooplankton abundance in Amini and Kadmat islands of Lakshadweep
}

\author{
Molly Varghese*, Rani Mary George'1, S. Jasmine', P. Laxmilatha, K. R. Sreenath², P. R. Behera³, \\ V. J. Thomas and J. Kingsley' \\ Central Marine Fisheries Research Institute, Kochi - 682 018, Kerala, India. \\ 'Central Marine Fisheries Research Institute,Vizhinjam Research Centre, Thiruvananthapuram - 695 521, Kerala, India. \\ 2 Central Marine Fisheries Research Institute, Veraval Regional Centre,Veraval-362269, Gujarat, India. \\ ${ }_{3}^{3}$ Central Marine Fisheries Research Institute,Visakhapatnam Regional Centre, Visakhapatnam-530 003, Andhra Pradesh, India. \\ *Correspondence e-mail: mollykandathil@hotmail.com
}

Received: 17 Mar 2015, Accepted: 15 May 2015, Published: 5 Jun 2015

\begin{abstract}
Studies on zooplankters collected from the lagoons of Amini and Kadmat islands of Lakshadweep Archipelago were carried out based on a survey conducted during January - February, 2014. The displacement volume of zooplankton in Amini and Kadmat were 58.35 and 15 $\mathrm{ml}$ per $100 \mathrm{~m}^{3}$ respectively. The density was also higher in Amini than in Kadmat which is estimated as 64480 and 47726 numbers per $100 \mathrm{~m}^{3}$ respectively. A total of twentyone groups of zooplankters viz., copepods, ostracods, chaetognaths, Lucifersp., medusae, doliolids, mysids, tintinnids, euphausiids, appendicularians, siphonophores, cladocera, amphipods, isopods, polychaete larvae, prawn larvae, crab larvae, squilla larvae, molluscan larvae, fish eggs and fish larvae were recorded from these two ecosystems. Groupwise studies indicated the dominance of copepods in Amini forming $40 \%$ while in Kadmat, the maximum was contributed by crab larvae (50\%). The dominance of crab larvae in Kadmat was due to a swarm of zoea stage of crab at station 2 in the western side of the island. Among the copepods, calanoid copepods contributed the maximum with $71 \%$ in Amini and $81 \%$ in Kadmat. Followed by the dominance of copepods in Amini, ostracods (33\%) and crab larvae (14\%) formed major
\end{abstract}

components. In Kadmat, copepods formed the second dominant group which contributed $20 \%$ followed by prawn larvae (11\%), ostracods (6\%) and the share by other groups were less than $5 \%$. Comparative studies on the occurrence of different groups of zooplankters in these two island ecosystems showed that copepods and ostracods were very much higher in Amini than in Kadmat while, crab larvae contributed more in Kadmat which was due to the swarming of zoea stage of crab. Both qualitative and quantitative abundance of zooplankters in these two ecosystems are presented and discussed.

Keywords: Zooplankton, coral reef ecosystem, distribution, Lakshadweep island.

\section{Introduction}

Zooplankters play an important link in the food chain of marine ecosystems. In coral reef ecosystems, they serve as food for corals, a variety of other invertebrates and reef fishes. As the plankters play an important role in the health 
of an aquatic ecosystem, the study on these resources in the productive aquatic systems of Lakshadweep is important. While searching through the literature, we can see that not much work was carried out on plankters of Lakshadweep ecosystems. Pratap et al. (1977) studied zooplankton at Kavaratti, Agatti and Suhelipar, while, Achuthankutty et al. (1989) dealt with zooplankton composition of Kalpeni and Agatti atolls. Girijavallabhan et al. (1989) studied zooplankters of Kadmat, Kiltan, Chetlat, Agatti, Kalpitti, Bangaram, Bitra, Kavaratti, Suhelipar, Androth, Minicoy and Kalpeni. Goswami and Goswami (1990) gave an account on diel variation in zooplankton of Minicoy lagoon and Kavaratti atoll. In 1997, Suresh and Mathew studied on zooplankton in Kavaratti atoll while Nasser et al. (1998) worked on zooplankton at Minicoy lagoon. Casanova and Nair (1999) gave an account on Sagitta from Agatti lagoon while, Bhalla et al. (2007) made a review on foraminiferal studies in Laccadives Islands. Jose et al. (2010) made a hierarchical analysis of zooplankton assemblages over semidiel pattern in the lagoon of Kavaratti atoll. Recently, Robin et al. (2012) studied planktonic communities and their trophic interactions in Kavaratti waters. Eventhough a very few studies were undertaken on zooplankters of Kadmat, no studies were carried out on zooplankton from Amini so far. Hence, an attempt is made here to study the qualitative and quantitative abundance of zooplankters in Amini and Kadmat lagoons of Lakshadweep and this is the first report on zooplankton from lagoon of Amini island.

\section{Material and methods}

Zooplankton samples were collected from different stations in the lagoon areas of Amini and Kadmat Islands of Lakshadweep during January - February, 2014. Amini island is a small island having a length of $3 \mathrm{~km}$ with a very narrow lagoon area and that too will be exposed during low tide. Hence, samples could be taken from only one station in the western side of the island. Kadmat island is very long, having a maximum length of $11 \mathrm{~km}$ with a large lagoon area extending upto $1.5 \mathrm{~km}$ from coastline and hence samples were taken from 3 stations (Fig.1).

Of these 3 stations, stations 1 and 2 were located well inside the lagoon and station 3 in the reef break zone. The distance between station 1 and 2 was $2.8 \mathrm{~km}$ and station 3 was 1.4 $\mathrm{km}$ away from station 2 . Zooplankton samples were collected using a conical net having a mesh size of 400 microns by towing the net by a boat at 0.1 knot speed for 10 minutes. The collected samples were preserved in $4 \%$ formaldehyde solution and examined under a stereozoom microscope for identification and enumeration. Both qualitative as well as quantitative estimations were made. Plankters were identified upto group level and expressed as numbers per $100 \mathrm{~m}^{3}$ of

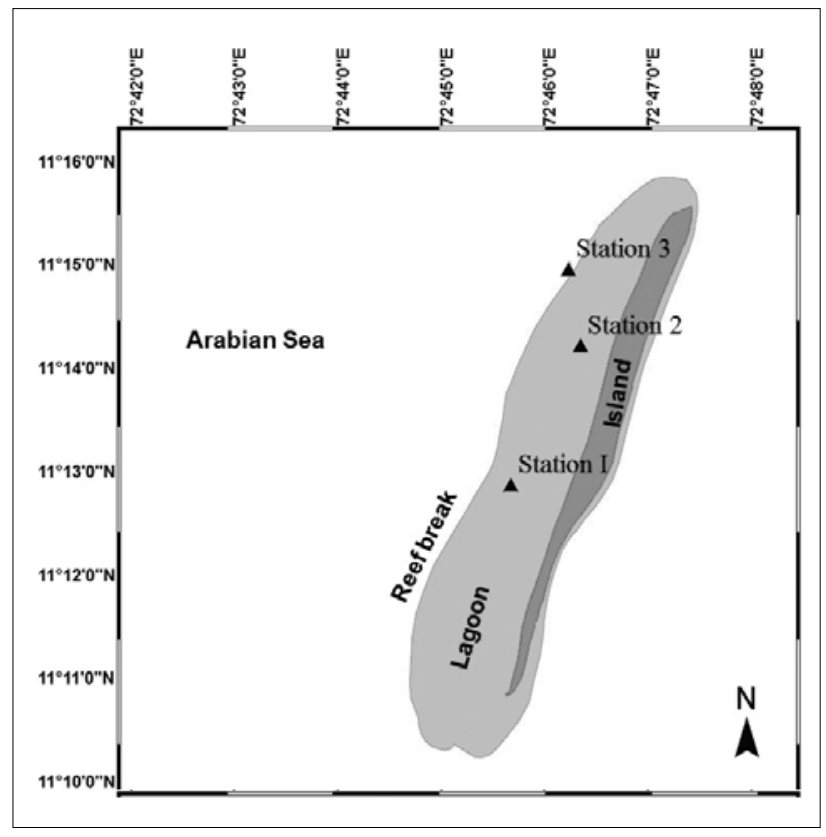

Fig.1. Map showing sampling stations in Kadmat

water. The abundance of zooplankters in Amini and Kadmat islands was also estimated.

\section{Results and discussion}

Qualitative and quantitative abundance of different groups of zooplankters in Amini and Kadmat lagoons revealed the occurrence of twentyone groups viz. copepods, ostracods, chaetognaths, polychaete larvae, Lucifer sp., medusae, doliolids, mysids, tintinnids, euphausiids, appendicularians, siphonophores, cladocera, amphipods, squilla larvae, isopods, prawn larvae, crab larvae, molluscan larvae, fish eggs and fish larvae. The abundance and distribution of these groups in the lagoons of Amini and Kadmat Islands are presented.

\section{Abundance of zooplankters in Amini}

The displacement volume of zooplankton was estimated as $58.35 \mathrm{ml}$ per $100 \mathrm{~m}^{3}$ of water. Groupwise studies indicated the availability of fifteen groups viz. copepods, euphausiids, ostracods, chaetognaths, Lucifer sp., medusae, doliolids, mysids, appendicularians, tintinnids, polychaete larvae, prawn larvae, crab larvae, molluscan larvae and fish eggs and their distribution in Amini lagoon is depicted in Fig.2.

A total of 64480 number of zooplankters were observed per $100 \mathrm{~m}^{3}$ of water in Amini. From lagoon of Kavaratti waters, Robin et al. (2012) recorded 64800 numbers per $100 \mathrm{~m}^{3}$ which is close to the numbers recorded from Amini during the present study which indicate the similarity in terms of secondary productivity in these two ecosystems. Among the 15 groups of zooplankters recorded from Amini, copepods were 


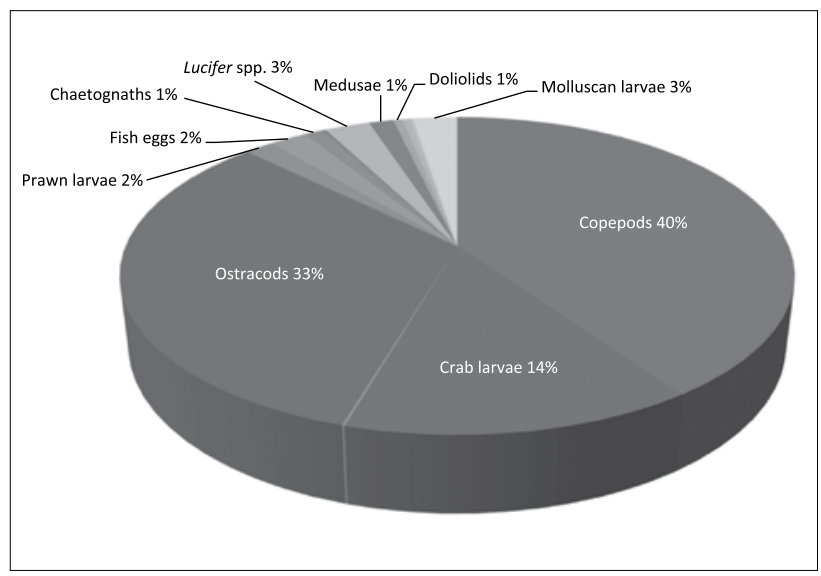

Fig.2. Distribution of zooplankters in Amini

found to be the most dominant group with a share of $40 \%$. This was followed by ostracods (33\%), crab larvae (14\%) and rest of the groups contributed only less than $5 \%$ each. Among the copepods, calanoid copepods were found to dominate with $71 \%$, followed by cyclopoids (27\%) and harpacticoids (2\%). Swarming of ostracods was observed in this area. The dominance of copepods among zooplankton to the tune of $53.77 \%$ and $44.63 \%$ from the lagoons of Agatti and Suhelipar respectively was noticed by Pratap et al. (1977).

\section{Abundance of zooplankters in Kadmat}

The displacement volume of zooplankton collected was estimated as $15 \mathrm{ml}$ per $100 \mathrm{~m}^{3}$ of water. Groupwise studies indicated the availability of nineteen groups viz. copepods, ostracods, chaetognaths, Lucifer sp., medusae, doliolids, mysids, tintinnids, polychaete larvae, siphonophores, cladocera, amphipods, isopods, prawn larvae, crab larvae, squilla larvae, molluscan larvae, fish eggs and fish larvae. In another study conducted by Integrated Coastal and Marine Area Management (ICMAM, 2001) during 1998-99 also recorded nineteen groups of zooplankters from Kadmat which is in agreement with the present study. Groupwise distribution of zooplankters in Kadmat lagoon is depicted in Fig.3.

A total of 47726 numbers of zooplankters were recorded per $100 \mathrm{~m}^{3}$ of water in the lagoon of Kadmat. In another study conducted by ICMAM (2001), a maximum of 32600 numbers of zooplankters per $100 \mathrm{~m}^{3}$ of water was reported from Kadmat. Among different groups observed, the maximum was contributed by crab larvae (50\%), followed by copepods $(20 \%)$, prawn larvae (11\%), ostracods (6\%) and the rest of the groups contributed only less than $5 \%$ each in the present study. Very high share of crab larvae to the tune of $50 \%$ was due to a swarm of crab larvae especially zoea stage noticed at station 2.0ccurrence of swarms of certain zooplankton groups occasionally is a common phenomenon and this may be associated with the

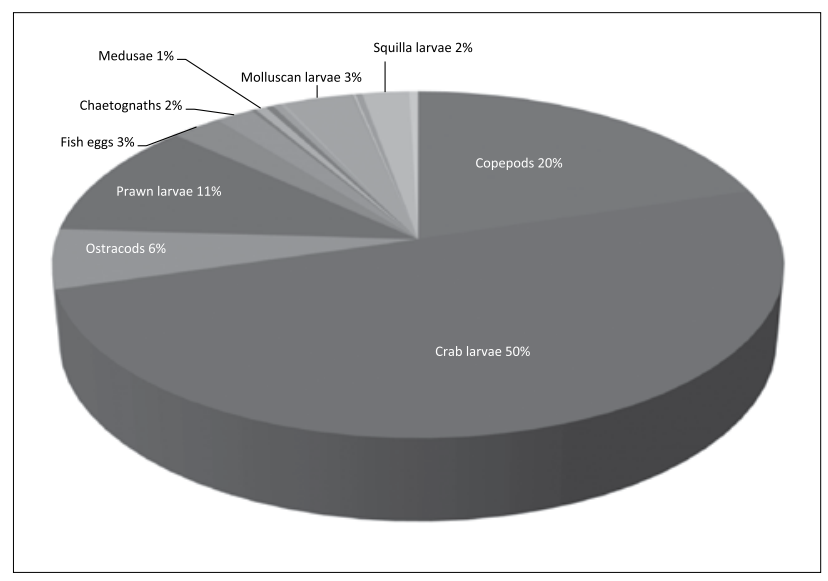

Fig.3. Distribution of zooplankters in Kadmat

prevailing physico-chemical characteristics of the region. At station 2, 69281 numbers of crab larvae were noticed per 100 $\mathrm{m}^{3}$ of water, while, in other two stations crab larvae observed were 333 and 2267 numbers per $100 \mathrm{~m}^{3}$ of water respectively. The abundance of decapod larvae in lagoon area of Kadmat was also recorded by Girijavallabhan et al. (1989). They have reported the dominance of decapod larvae $(59.46 \%)$ and share of copepods as $13.6 \%$. In the present study also decapod larvae dominated with $61 \%$ and share of copepods as $20 \%$ which indicate that the ecosystem remains rich even after 25 years. Meroplankton as an important component of zooplankton was also reported by Goswami and Goswami (1990) from Minicoy lagoon and by Achuthankutty et al. (1989) from lagoons of Kalpeni and Agatti. Achuthankutty et al. (1989) have also observed that brachyuran zoea constituted the major share of meroplankton in Kalpeni and Agatti, which is true in the present study in Kadmat. Among the copepods, calanoids formed major share $(81 \%)$, followed by cyclopoids $(14 \%)$, harpacticoids $(2 \%)$ and nauplii of copepods formed $3 \%$ in the present study. In a study conducted by ICMAM (2001) in Kadmat, with respect to number of species of copepods, maximum numbers of species among the copepods were recorded under Calanoida.

\section{Distribution of zooplankters in Amini and Kadmat - a comparison}

The composition of different zooplankton groups in Amini and Kadmat showed considerable variations. When compared to Kadmat, the concentration of zooplankters was more in Amini and the numbers per $100 \mathrm{~m}^{3}$ of water were 47726 and 64480 in Kadmat and Amini respectively. Volume of zooplankton recorded was also more in Amini than in Kadmat. One of the possible reasons for less abundance of zooplankton in Kadmat when compared to Amini can be explained in terms of turbidity. During the present study, the turbidity was 0.33 NTU in Amini whereas in Kadmat it 
was 0.99 NTU (personal communication). The existence of inverse relationship between zooplankton and turbidity is an established fact (Rai, 1974; Rao, 1985) and this is true in the present study also. Another reason for the less concentration of zooplankton in Kadmat may be due to the blooming of the blue green algae, Scytonema sp. in Kadmat, which was also studied simultaneously during the study. Among the different genera of Phytoplankters, the genus Scytonema formed $41 \%$ in Kadmat while it was only $5 \%$ in Amini (personal communication). Groupwise studies indicated the dominance of mainly copepods and ostracods in Amini, while crab larvae, copepods and prawn larvae dominated in Kadmat. The abundance of both crab and prawn larvae in Kadmat is an indication of the availability of rich crustacean resources in Kadmat. This is supported by the fact that all the 89 species of crustacean resources occurring in Lakshadweep are available in Kadmat also (ICMAM, 2001).

As there is no recent reports on zooplankters are available from Kadmat and no previous report from Amini, the present study is important. As this study is based on a survey, further studies based on regular collections have to be carried out in these ecosystems to arrive at more meaningful conclusions.

\section{Acknowledgements}

The authors are thankful to the Director, C.M.F.R.I. and to Dr. K. K. Joshi, Head of Marine Biodiversity Division, for their encouragements during the course of this work.

\section{References}

Achuthankutty, C. T., S. R. S. Nair, P. Haridas and M. Madhupratap. 1989. Zooplankton composition of the Kalpeni and Agatti Atolls, Lakshadweep Archipelago. Indian J. Mar. Sci., 18 (3): 151-154.

Bhalla, S. N., N. Khare, D. H. Shanmukha and P. J. Henriques. 2007. Foraminiferal studies in nearshore regions of western coast of India and Laccadives Islands: A review. Indian J. Mar. Sci., 36(4): 272-287.

Casanova, J. P. and V. R. Nair. 1999. A new species of the genus Sagitta (Phylum Chaetognatha) from the Agatti Lagoon (Laccadive Archipelago, Indian Ocean) with comments on endemism. Indian J. Mar. Sci., 28(2): 169-172.

Girijavallabhan, K. G., I. David Raj and S. V. Alavandi.1989. Hydrobiology of lagoons. In: C. Suseelan (Ed.) Marine living resources of the union territory of Lakshadweep - An Indicative survey with suggestions for development. Bull. Cent. Mar. Fish. Res. Inst., Cochin, 43: 200-211.

Goswami, S. C. and Usha Goswami. 1990. Diel variation in zooplankton in Minicoy lagoon and Kavaratti atoll (Lakshadweep islands). Indian J. Mar. Sci., 19: 120-124.

ICMAM, 2001.Critical habitat information system of Kadmat Island-Lakshadweep. Report of Integrated Coastal and Marine Area Management Project Directorate, Chennai, July 2001, 201p.

Jose Jean, J., P. Udayakumar, V. J. Ajimon, R. Shibu, K. Narendra Babu and R. S. Baiju. 2010. Hierarchical analysis of zooplankton assemblages over semidiel pattern in the lagoon of Kavaratti atoll, Lakshadweep Archipelago, India. Curr. Res. J. Biol. Sci., 2(4): 294-298.

Nasser, A. K. V., P. Siraimeetan and P. M.Aboobaker. 1998. Zooplankton abundance and distribution at Minicoy Lagoon, Lakshadweep. Indian J. Mar. Sci., 27(34): 346-350.

Pratap, M. M., M. V. M. Wafar, P. Haridas, B. Narayanan, P. G. Menon and P. Sivadas. 1977. Comparative studies on the abundance of zooplankton in the surrounding sea and lagoons in the Lakshadweep. Indian J. Mar. Sci., 6(2): 138-141.

Rai, H. 1974. Limnological studies on the River Yamuna at Delhi, India, Part II. The dynamics of potamoplankton populations in the River Yamuna. Archiv fuer Hydrobiologie, 73(4):492-517.

Rao, D. S. K. 1985. A note on the plankton of a freshwater impoundment in Karnataka. Indian J. Fish., 32(1): 135-139.

Robin, R. S., Pradipta R. Muduli, K. Vishnu Vardhan, A. Nagarjuna, T. Nallathambi Rajani K. Mishra and T. Balasubramanian. 2012. Planktonic communities and trophic Interactions in the Kavaratti waters, Lakshadweep Archipelago, India. Int. J. Ecosyst., 2(2): 5-18.

Suresh, V. R. and K. J. Mathew. 1997. Zooplankton ecology in Kavaratti Atoll, Lakshadweep, India. Indian J. Fish., 44 (3): 271-277. 